\title{
Challenges and Mortality after Neck of Femur Fractures in Elderly Patients; Experience of a Small District Hospital
}

\author{
Syed Mohsin Ali ${ }^{1}$, Jagadish Prabhu ${ }^{2}$, Hamza Reda Elsaid Gomaa ${ }^{3}$, Fahad Al-Khalifa ${ }^{1}$ and A Lynch ${ }^{4}$ \\ ${ }^{1}$ Consultant Orthopedic Surgeon, Bahrain Defense Forces Hospital, Bahrain \\ ${ }^{2}$ Chief Resident Orthopedic, Bahrain Defense Forces Hospital, Bahrain \\ ${ }^{3}$ Resident Bahrain Defense Forces Hospital, Bahrain \\ ${ }^{4}$ Consultant Orthopedic Surgeon, Letterkenny General Hospital, Ireland \\ Submission: March 20, 2018; Published:April 02, 2018 \\ *Corresponding author: Syed Mohsin Ali, Consultant Orthopedic Surgeon, Bahrain Defense Forces Hospital. AL-Riffa Avenue, Bahrain, \\ Tel: +97332309230; Email: smali2233@yahoo.com
}

\begin{abstract}
Background: The incidence of fractures is increasing due to the aging population. The death rate within one year due to neck of femur fractures is reported as up to $35 \%$ and the average stay in hospital has been documented as up to four weeks or more. The purpose of our study was to identify the challenges and factors which can reduce mortality rate in elderly patients with neck of femur fractures.

Method: We carried out a retrospective study of patients admitted to our hospital with neck of femur fractures between 12 months. 53 necks of femur fractures in 48 patients were reviewed. We recorded sex, age, pre-admission residence, mobility of patients, type of fractures, interval between admission and surgery, associated medical problems and other injuries. We also recorded any effect of mortality rate due to preexisting medical problems cause of delay in surgical management, post-operative complications, hospital stay, and destination after surgery.

Results: Average age in this group was 80.73 years. High mortality rate within the first 12 months of injury was found in patients who were operated after 72 hours of hospitalization. Increased mortality rate was also associated with previous medical problems. There was shorter hospital stay for patients who had surgery within 48 hours of admission.

Conclusion: Although this study group was small, but we found that mortality rate after fractured neck of femur can be reduced by early surgical intervention and consideration of co-morbidities with a Multi-Disciplinary Team (MDT) approach.
\end{abstract}

Keywords: Fracture; Delayed; Complications; Mortality; MDT (Multi disciplinary approach)

Abbreviations: CVA: Cerebrovascular Accident; PVD: Peripheral Vascular Disease

\section{Introduction}

Over 320,000 hip fractures reported in North America each year and they are associated with a mortality rate ranging from $14 \%$ to $36 \%$ within 1 year of surgery [1]. The incidence of fracture neck of femur is increasing with steady increase in elderly population [2]. Different studies have shown longer hospital stay (more than 4 weeks) for elderly patients with neck of femur fracture [3]. The treatment of these fragile bone fractures has conventionally been influenced by a fear of repeated procedures due to late complications such as failure of metal work, a vascular necrosis of femoral head and non-union of fractures [2]. Early versus delayed surgery is still debatable, although several large series of audits and reviews on proximal femur fractures did not show much difference in the fracture out come between early or delayed surgery [4]. It is believed that the time factor interval between injury and surgical intervention may affect the outcome and mortality rate within the first twelve months of fracture fixation [5]. According to one study, delay is associated with increased mortality the association still exists but is reduced after management of pre-existing medical conditions [6]. It has been reported that delay in surgery can increased the risk of death and morbidity even in physiologically stable patients $[7,8]$.

The purpose of our study was to identify the effects of timing of surgery and MDT approach on the post-operative mobility, hospital stay, complications, in-hospital deaths and postoperative mortality after hip fracture in elderly patients at our hospital. 


\section{Orthopedics and Rheumatology Open Access Journal}

\section{Materials and Method}

We carried out a retrospective study with interval of 18 months from diagnosis of neck of femur fracture in 48 patients admitted to our hospital. These patients were assessed through their clinical notes and a telephone survey was performed to record the mortality. 53 necks of femur fractures in 48 patients were reviewed. Head of femur, intratrochanteric and subtrochanteric fractures were excluded from this study on basis of x-ray review. Fractures were classified according to Garden Classification (Figure 1). We recorded sex, age, and preadmission residence, mobility of patients, associated medical problems and other injuries or fractures. We also recorded any cause of delay in surgical management, post-operative complications, hospital stay, discharge destination after surgery and mortality rate after surgery. Interval between admission and surgery was also recorded, with early surgery being within 48 hours and late being after 48 of admission. Due to small number of patient cohort statistical analysis was not done.

\section{Garden classification (Figure 1)}

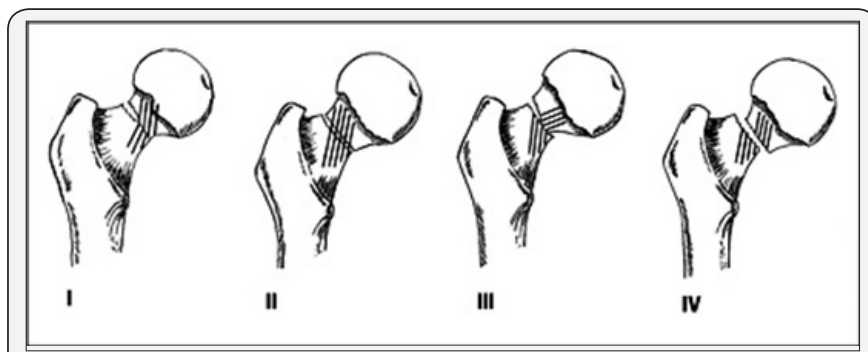

Figure 1: Garden Classification.

i. Incomplete Stable fracture with impaction in valgus.

ii. Complete but non-displaced with two group of trabeculle in line.

iii. Completely displaced with varus with all three trabeculle disturb.

iv. Completely displaced with no contact between the fracture fragments Types of fractures were divided into two groups based on Garden Classification:

a. Group-1 Type I and II (undisplaced fracture).

b. Group -2 with Type III and IV (displaced fracture).

Results

Our analysis showed out of 48 patients with neck of femur fractures, 10 were male and 38 were female, with an average age of 80.73 (range from 57-92). 5 patients had a previous history of a contra-lateral hip fracture. Out of 53 fractures, 21 fractures were classified as un-displaced and 32 as displaced fractures. At the time of injury 43 were living in their own home and 10 patients were residing at a nursing home. Prior to injury 37 patients were mobilizing independently, 16 were using some sort of walking aid due to some associated medical condition (Figure 2). Five patients had other associated injuries at time of injury, two wrists, one scaphoid and humerus fracture. One patient had head injury and surgery has to delay due to head injury observation protocols.

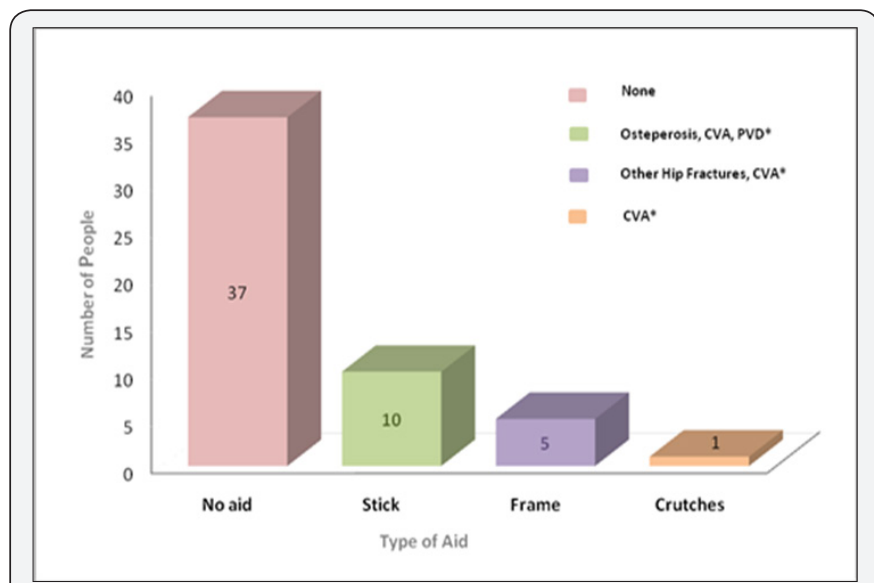

Figure 2: Mobility of patients.

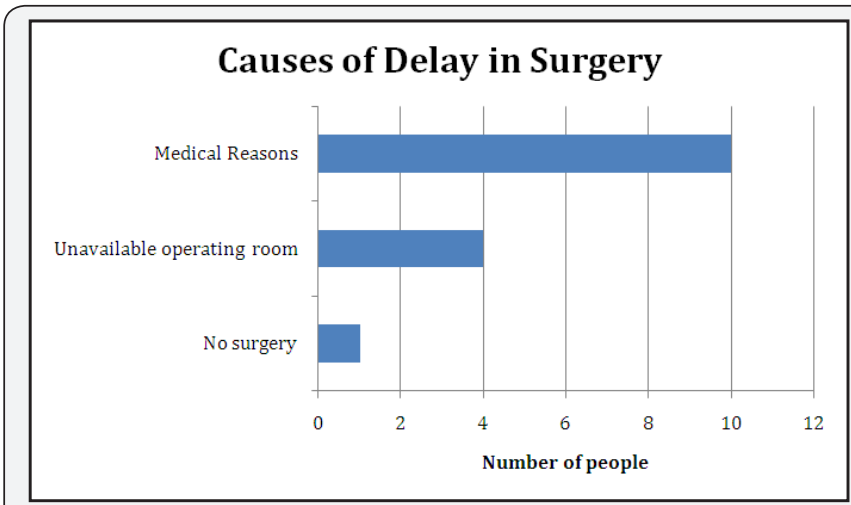

Figure 3: Causes of delay in surgery.

When we reviewed past medical history we found that 48 patients had some pre-existing medical problem. Table 1. Most common medical problem was noted were related to cadivascular system. 33 underwent hip hemiarthroplasty and 21 hips were fixed with either Cannulated screw or Dynamic Hip Screw (Table 2). We noted 38 fractures were fixed within 24 hours of admission, 8 between 24-48 hours, 3 between 48-72 hours while the remaining 4 had their surgery after 72 hours from admission. Main reason behind the delay in surgery was preexisting medical conditions which require medical optimization prior to surgery and other cause was operating time viability (Figure 3). Four patient surgeries were also delayed to busy emergency trauma schedule.

Average stay in hospital was 13.13 days (range 12-36 days). 23 patients went pre-injury residence and 25 required secondary level care for rehabilitation. Post operatively only one patient had superficial wound infection which was treated oral antibiotics and 16 patients had some medical problem which was treated with support medical team. While assessing the mortality rate in this group of patients, there were no in hospital death recorded. 9 patients out of 48 patients (18.75\%) died within 18 months 
of injury. The average age of this these patients, was 86.9 years with an average stay in hospital of 13.9 days (range 6-30 days).

Table 1: Associated medical problems at admission post operatively and associated mortality.

\begin{tabular}{|c|c|c|c|}
\hline & $\begin{array}{l}\text { Medical } \\
\text { Problem }\end{array}$ & $\begin{array}{c}\text { No. of } \\
\text { Patients }\end{array}$ & $\begin{array}{c}\text { Mortality After } 18 \\
\text { Months }\end{array}$ \\
\hline \multirow{10}{*}{ Pre-Op } & Cardiac & 30 & - \\
\hline & $-\mathrm{BP}^{*}$ & 14 & 3 \\
\hline & -IHD* & 13 & 1 \\
\hline & $-\mathrm{CCF}^{*}$ & 3 & - \\
\hline & COPD* & 9 & - \\
\hline & $\mathrm{CVA}^{*}$ & 4 & - \\
\hline & Epilepsy & 3 & 1 \\
\hline & Diabetes & 4 & - \\
\hline & Osteoporosis & 4 & - \\
\hline & Dementia & 3 & 3 \\
\hline \multirow{11}{*}{ Post-OP } & Confusion & 4 & 1 \\
\hline & Atrial Fibrillation & 3 & 2 \\
\hline & MI* & 2 & - \\
\hline & $\mathrm{CCF}^{*}$ & 3 & 1 \\
\hline & $\mathrm{CVA}^{*}$ & 2 & - \\
\hline & UTI* & 2 & - \\
\hline & $\mathrm{BP} *$ & 1 & - \\
\hline & Infection & & - \\
\hline & i. & Chest & 1 \\
\hline & ii. & Wound & 1 \\
\hline & Dislocation & 1 & - \\
\hline
\end{tabular}

*B.P Blood Pressure; IHD- Ischemic Heart Disease; CCFCongestive Cardiac Failure; COPD- Chronic Obstructive Pulmonary Disease; CVA- Cerebro Vascular Accident; MIMyocardial Infarction; UTI- Urinary Tract Infection.

Table 2: Type of Fixation.

\begin{tabular}{|c|c|}
\hline Type of Fixation & No. of Patients \\
\hline Hemiarthroplasty & 33 \\
\hline i. Unipolar & 32 \\
\hline ii. Bi-polar & 01 \\
\hline Canulated screw & 10 \\
\hline DHS & 10 \\
\hline
\end{tabular}

Table 3: Timing of surgery and mortality rate.

\begin{tabular}{|c|c|c|c|}
\hline $\begin{array}{c}\text { Time of } \\
\text { Surgery from } \\
\text { Injury }\end{array}$ & No. of Patients & $\begin{array}{c}\text { No. of Deaths } \\
\text { in } \mathbf{1 8} \text { Months }\end{array}$ & \% of Mortality \\
\hline$<72 \mathrm{hrs}$ & 46 & 5 & $13.5 \%$ \\
\hline$>72 \mathrm{hrs}$ & 4 & 4 & $100 \%$ \\
\hline
\end{tabular}

All patients operated after 72 hours in this study had mortality within first 18 months of injury (Table 3).

\section{Discussion}

Aging population is rapidly increasing, age related medical and surgical problems are a big challenge for medical health provider globally. By 2050, the population who are 65 or more years of age is estimated to be about 1.5 billion, representing $16 \%$ of the global population by WHO estimation [9]. Neck of femur (NOF) fractures are the most common injury and cause of admission in hospital among elderly population and a significant burden on healthcare system. Because such patients require longer hospital stay for their acute and chronic medical care [10]. Garden classification is the most common classification used for describing neck of femur fracture. Reliability of classification improves when the Garden classification is simplified in a classification using the terms: 'non-displaced' or 'displaced' fractures [11].

There are many different methods for neck of femur fracture fixation which have been described in orthopedic literature. Common methods of hip fracture management are DHS, screw and plate fixation, hemiarthroplasty or total hip replacement (THR). Decisions of management are according to fracture patron, functional requirements, patient age, co-morbidity, and risk factors for surgery and anesthesia [9].

During our literature review we found that early treatment minimizes the length of time a patient is confined to bed rest, thereby reducing the risk for associated complications, such as pressure sores, deep vein thrombosis and urinary tract infections. However, those favoring delaying surgery beyond the guideline recommendations believe that this approach is required to medically optimize patients, and therefore decrease the risk for perioperative complication [12]. We found in our study medical optimization of these patients prior to surgery with MDT approach effects the outcome on hospital stay and reduce the risk of in-hospital mortality rate. Those patients who were operated with in first 48 hours of injury had low mortality rate, shorter post operative hospital stay and lesser complications. During this study we found local challenges like emergency operative room availability and secondary level care after treatment are important factors as well [13].

\section{Conclusion}

In conclusion mortality rate and post operative complications after sustaining a fracture to the neck of femur in elderly patients can be reduced by Multi Disciplinary Team approach, early surgical intervention and mobilization. With the numbers given, there is no statistical correlation between the post-operative mortality and operative delay from admission, although 4 patients having surgery after 72 hours deceased within 18 months of follow up. We have not used statistical analysis for comparing the patients because the series was too small and advice for multi-center studies to look role of MDT approach for this group of patients. 


\section{Conflict of Interest}

We like to declare that there is no conflict of interest.

\section{References}

1. Mundi S, Pindiprolu B, Simunovic N, Bhandari M (2014) Similar mortality rates in hip fracture patients over the past 31 years: A systematic review of RCTs. Acta Orthopaedica 85(1): 54-59.

2. Grimes JP, Gregory PM, Noveck H, Butler MS, Carson JL (2002) The effects of time to surgery on mortality and morbidity in patients following hip fracture. Am J Med 112(9): 702-709.

3. Youm T (2000) Effects of previous cerebrovascular accident on the outcome after hip fracture. Journal of Orthopaedic Trauma 14(5): 329334.

4. Toh EM, Sahni V, Acharya A, Denton JS (2004) Management of intracapsular femoral neck fractures in the elderly; is it time to rethink our strategy? Injury 35(2): 125-129.

5. Boyce WJ, Vessey MP (1985) Rising incidence of fracture of the proximal femur. The Lancet 325(8421): 150-151.

6. Bottle Alex, Paul Aylin (2006) Mortality Associated with Delay in Operation after Hip Fracture: Observational Study. BMJ 332(7547): 947-951.

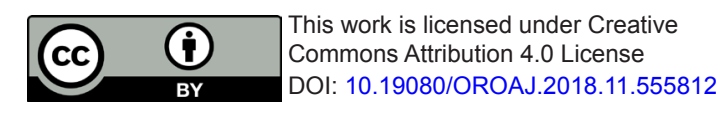

7. Rogers FB, Shackford SR, Keller MS (1995) Early fixation reduces morbidity and mortality in elderly patients with hip fractures from low-impact falls. J Trauma 39(2): 261-265.

8. Fox HJ, Pooler J, Prothero D, Bannister GC (1994) Factors affecting the outcome after proximal femoral fractures. Injury 25: 297-300.

9. Lin WT, Chao CM, Liu HC, Li YJ, Lee WJ (2015) Short-Term Outcomes of Hip Fractures in Patients Aged 90 Years Old and Over Receiving Surgical Intervention. PLoS ONE 2015: 10(5).

10. Udovicich C, Page D, Huq M, Clifforth S (2015) Neck of femur fracture management by general surgeons at a rural hospital. The Australasian Medical Journal 8(5): 154-160.

11. Van Embden D, Rhemrev SJ, Genelin F, Meylaerts SA, Roukema GR (2012) The reliability of a simplified Garden classification for intracapsular hip fractures. Orthop Traumatol Surg Res 98(4): 405408.

12. Simunovic N, Devereaux P, Bhandari M (2011) Surgery for hip fractures: Does surgical delay affect outcomes? Indian Journal of Orthopaedics 45(1): 27-32.

13. Hapuarachchi KS, Ahluwalia RS, Bowditch MG (2014) Neck of femur fractures in the over 90s: a select group of patients who require prompt surgical intervention for optimal results. J Orthop Traumatol 15(1): 13-19.

\section{Your next submission with Juniper Publishers will reach you the below assets}

- Quality Editorial service

- Swift Peer Review

- Reprints availability

- E-prints Service

- Manuscript Podcast for convenient understanding

- Global attainment for your research

- Manuscript accessibility in different formats

( Pdf, E-pub, Full Text, Audio)

- Unceasing customer service

Track the below URL for one-step submission https://juniperpublishers.com/online-submission.php 